\title{
Mulheres em \\ Cooperativas Rurais \\ Virtuais: \\ Reflexões \\ Sobre Gênero e Subjetividade
}

Women in Virtual Rural Coops:

Reflections on Gender and Subjectivity

Mujeres en Cooperativas Rurales Virtuales: Reflexiones Sobre Género y Subjetividad

Giovana Ilka Jacinto Salvaro,

Dimas de Oliveira Estevam \&

Daiane Fernandes Felipe

Universidade do

Extremo Sul Catarinense

http://dx.doi.org/10.1590/1982-3703000262013

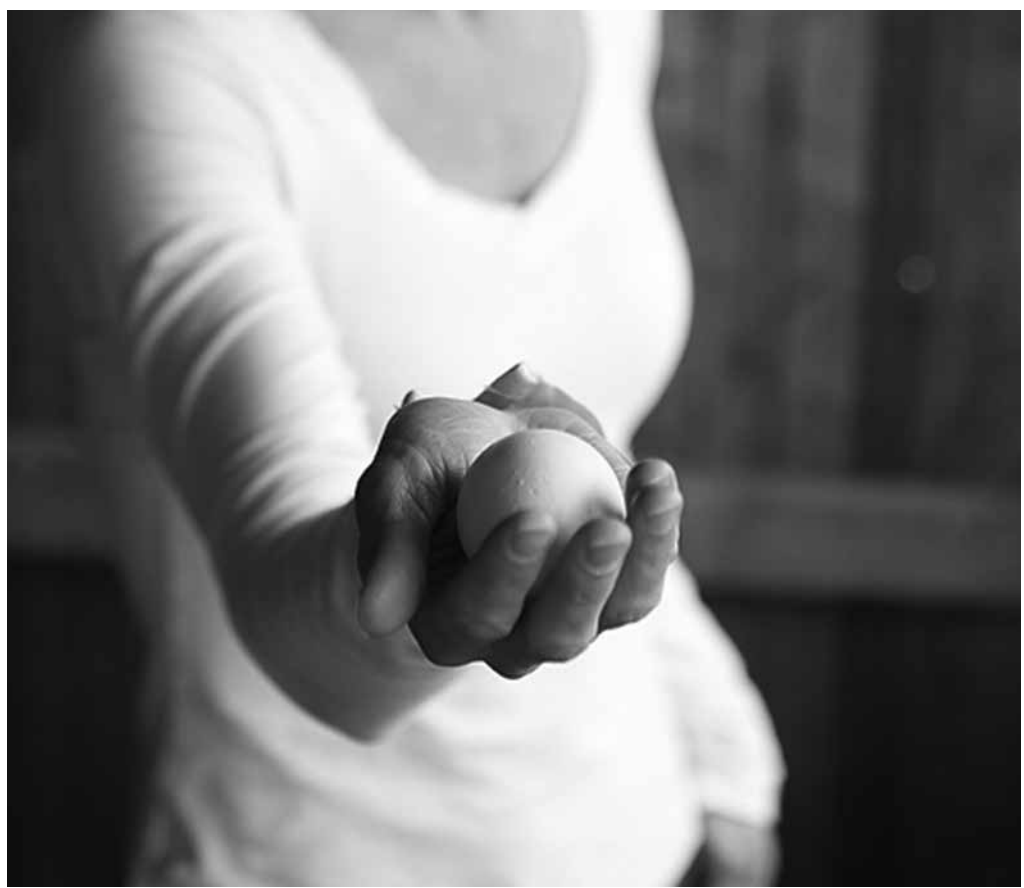


Resumo: Este artigo busca apresentar uma reflexão sobre gênero e subjetividade, a partir da participação de mulheres em cooperativas rurais virtuais localizadas em municípios da região sul de Santa Catarina. Conforme define a literatura estudada, tal modelo de cooperativa se diferencia do modelo tradicional, pois, entre outros aspectos, não possui sede fixa, reúne um grupo de 20 a 30 agricultores e movimenta uma grande variedade de produtos em pequenas quantidades. Trata-se de uma análise ampliada com base em dados coletados em pesquisa desenvolvida no período de 2011-2012 (PIBIC-UNESC/CNPq). A pesquisa foi qualitativa e os dados foram obtidos por meio da entrevista semiestruturada. Foram entrevistadas dez mulheres, com idades entre 36 e 54 anos, participantes de três cooperativas. As entrevistas foram gravadas, transcritas e analisadas de acordo com procedimentos da análise de conteúdo. Os resultados e discussão apresentam o processo de formação das cooperativas, a participação e os produtos comercializados pelas cooperadas; além de discorrer sobre a participação de mulheres em cooperativas rurais virtuais, a visibilidade social e o reconhecimento do trabalho feminino. Em grande medida, foi possível verificar que a participação de mulheres em cooperativas possibilitou benefícios não apenas financeiros, pela comercialização da produção, mas também reconhecimento social e subjetivo.

Palavras-chave: Trabalho feminino. Cooperativa de produção. Gênero. Subjetividade.

Abstract: This article aims to propose reflection on gender and subjectivity by analyzing the participation of women in virtual rural coops located in southern cities in the state of Santa Catarina. According to the literature studied, that coop model is different from the traditional one because, among other aspects, it does not have a fixed headquarters, it gathers a group of 20 to 30 farmers and it sells a wide range of products in small quantities. The study concerned refers to an extended analysis based on data collected from a research in the period between 2011 and 2012 (PIBIC - UNEC/CNPq). The research was qualitative and the data was obtained by semi-structured interviews. Ten women between the ages of 36 and 54 , who were members of three coops. were interviewed. The interviews were recorded, transcribed and analyzed according to procedures of content analysis. The results and the discussion show the formation process of coops, the participation and the products commercialized by the members and discuss the participation of women in virtual rural coops, the social visibility and the acknowledgement of women's work. Generally speaking, it could be noticed that women's participation in coops brought not only financial benefits due to the sales of produce, but also social and subjective acknowledgement.

Keywords: Women's work. Cooperative production. Gender. Subjectivity.

Resumen: Este artículo trata de presentar una reflexión sobre género y subjetividad, desde el punto de vista de la participación de mujeres en cooperativas rurales virtuales ubicadas en municipios de la región sur del Estado de Santa Catarina. Según define la literatura estudiada, dicho modelo de cooperativa se diferencia del modelo tradicional, puesto que, entre otros aspectos, no posee sede fija, reúne un grupo de 20 a 30 agricultores y circula una gran variedad de productos en pequeñas cantidades. El presente estudio se refiere a un análisis ampliado con base en datos recolectados en una investigación llevada a cabo en el periodo entre 2011 y 2012 (PIBIC - UNESC/CNPq). Dicha investigación fue cualitativa y los datos fueron obtenidos por medio de la entrevista semiestructurada. Fueron entrevistadas diez mujeres, con edades entre 36 y 54 años, participantes de tres cooperativas. Las entrevistas fueron grabadas, transcriptas y analizadas con arreglo a los procedimientos del análisis de contenido. Los resultados y la discusión presentan el proceso de formación de las cooperativas, la participación y los productos comercializados por las cooperadas; más allá de disertar acerca de la participación de mujeres en cooperativas rurales virtuales, de la visibilidad social y del reconocimiento del trabajo femenino. En gran medida, fue posible verificar que la participación de mujeres en cooperativas tornó posible el logro de beneficios no solamente financieros, por la comercialización del producto, sino también un reconocimiento social y subjetivo.

Palabras clave: Trabajo femenino. Cooperativa de produccion. Género. Subjetividad.

Este artigo busca apresentar uma reflexão sobre relações de gênero e subjetividade, a partir da participação de mulheres em cooperativas rurais virtuais localizadas em municípios da região sul de Santa Catarina. Trata-se de uma análise e reflexão ampliada com base em dados coletados em pesquisa desenvolvida no período de 2011-2012
(PIBIC-UNESC/CNPq). De forma mais ampla, a pesquisa originária buscou analisar modos de participação de mulheres em cooperativas virtuais. A pesquisa impôs o desafio de dialogar com diferentes campos do saber e, em grande medida, evidenciou a necessidade de produção de conhecimentos interdisciplinares sobre o tema. 
Para Paulilo

(1987), a divisão

do trabalho é

determinada

culturalmente

segundo as

atividades

executadas;

nesse caso, a

mulher executa

tanto os trabalhos

"leves" como

os "pesados". A

autora conclui da

seguinte forma:

"O trabalho

é 'leve' (e a

remuneração

é baixa), não

devido a suas

características, mas devido

à posição

ocupada na

hierarquia da

família por

aqueles que

executam o

trabalho" (Paulilo,

1987, p. 70).
Em uma perspectiva histórica, Bruschini (1993, p. 02) observa que "entre outros assuntos pertinentes à condição feminina, $\mathrm{O}$ tema trabalho foi privilegiado nos estudos de gênero, tendo sido o primeiro a logo conquistar o selo da legitimidade, inclusive nas universidades brasileiras". Segundo Bruschini, esse interesse, possivelmente, aconteceu por conta de dois fatores: a predominância do tema trabalho na teoria sociológica e a importância do tema para o feminismo, por seu "potencial transformador", na medida em que, quando remunerado, poderia se apresentar como uma estratégia para emancipar a dona de casa de determinado lugar subjugado na própria família.

É possível observar preocupações feministas e acadêmicas acerca do tema mulheres e trabalho. Bruschini (1993) observa que os estudos sobre o trabalho feminino no Brasil, inicialmente, tratavam da incorporação ou expulsão de tal força de trabalho pelo mercado capitalista. Posteriormente, os estudos começaram a analisar o espaço produtivo e sua relação com a família, considerando o trabalho feminino na interface com a esfera doméstica e esfera de produção. De acordo com Bruschini, a inclusão da temática divisão sexual do trabalho, como produto da preexistência de relações sociais entre os sexos, produziu um salto qualitativo no campo de estudo sobre o trabalho feminino. É oportuno também fazer referência ao estudo de Souza-Lobo (2011), que, entre outras questões, trata da interface relações de gênero e divisão sexual do trabalho, de modo a evidenciar que atividades femininas são marcadas pela hierarquia de gênero e apresentam desigualdades salariais e desqualificação.

Contemporaneamente, então, pode-se questionar qual a relevância de propor uma investigação sobre mulheres e trabalho em contextos rurais, especificamente, com foco nas relações de gênero e subjetividade?
Para Melo (2009, p. 167) "na atualidade a perspectiva feminista propõe uma abordagem transversal e multidisciplinar, que desenhe um quadro geral do papel feminino na sociedade, recuperando aquelas atividades ignoradas na lógica do mundo capitalista". Melo, especificamente, refere-se ao trabalho doméstico (em grande medida, ainda, desenvolvido por mulheres) e sua invisibilidade em relação ao que socialmente é considerado trabalho produtivo.

Estudos sobre o trabalho de mulheres em contextos rurais evidenciam também certa divisão sexual. Em uma perspectiva histórica, envolvendo estudos sobre o tema relações de gênero e trabalho em contextos rurais, no artigo clássico $O$ peso do trabalho leve, que trata do trabalho feminino rural no Noroeste do estado de São Paulo, Brejo Paraibano e Sul de Santa Catarina, Paulilo (1987) observa que atividades agrícolas são classificadas como leves e pesadas a partir de quem as realiza: mulheres e crianças realizam atividades consideradas "leves"; homens adultos realizam atividades consideradas "pesadas". Essa variação cultural e histórica, de acordo com a autora, produz valorações socioeconômicas diferenciadas para as atividades desenvolvidas por homens e mulheres, de forma que o critério para considerar uma atividade "pesada" ou "leve" é relativo. Para Paulilo (1987), a divisão do trabalho é determinada culturalmente segundo as atividades executadas; nesse caso, a mulher executa tanto os trabalhos "leves" como os "pesados". A autora conclui da seguinte forma: "o trabalho é 'leve' (e a remuneração é baixa), não devido a suas características, mas devido à posição ocupada na hierarquia da família por aqueles que executam o trabalho" (Paulilo, 1987, p. 70).

A partir do exposto, é possível considerar que a divisão sexual do trabalho na agricultura familiar constitui-se de acordo com questões de gênero, de modo a atribuir atividades 
diferentes para mulheres e homens. Antes de prosseguir com a discussão acerca da divisão sexual do trabalho rural, torna-se central retomar a emergência do gênero como categoria de análise. No artigo clássico intitulado Gênero - uma categoria útil de análise histórica, Scott (1995) evidencia a emergência, no final do século $X X$, da categoria para tratar de um sistema de relações sociais e proposta de feministas contemporâneas para explicar desigualdades entre homens e mulheres.

No presente artigo, o conceito de gênero é entendido e mobiliza a análise a partir de Butler (2003), autora que questiona a definição de gênero como "interpretação cultural do sexo" e ressalta que este é performativo e produz o sexo. $\mathrm{Na}$ análise de Butler, a performatividade de gênero é sempre a reiteração de uma norma ou conjunto de normas e, como efeitos produtivos do poder, constroem e regulam a materialidade dos corpos, garantindo a manutenção da hegemonia heterossexual e a inteligibilidade cultural.

Feitas tais considerações sobre o gênero, convém retomar alguns estudos sobre a divisão sexual do trabalho em contextos rurais ${ }^{1}$. Paulilo (1987, 2003, 2004), Brumer (2004) e Woortmann (1995) analisam questões relativas à divisão sexual do trabalho, proveniente de competências atribuídas historicamente a homens e mulheres. Conforme evidenciam os estudos citados, em contextos de agricultura familiar, sobremaneira, as mulheres são responsáveis por atividades domésticas (que incluem a limpeza da casa, criação dos filhos, o preparo de alimentos, entre outras) e os homens por atividades consideradas produtivas (administração da propriedade, plantio, colheita, comercialização, entre outras). Na direção apontada pelas autoras, ainda, em grande medida, a realização de atividades produtivas por mulheres é considerada "ajuda".
Tendo em vista que a divisão sexual do trabalho faz-se a partir da histórica divisão entre as esferas consideradas públicas e privadas, respectivamente, relacionadas ao trabalho produtivo e reprodutivo (doméstico), em contextos rurais, conforme Paulilo (2004), os limites de tal divisão não são assim tão claros. Comparado ao modo de produção capitalista que institui a separação entre as esferas de produção do trabalho (trabalho produtivo) e doméstica (trabalho não produtivo), Paulilo (2004) argumenta que no caso do campesinato não é fácil visualizar a separação entre unidade familiar e de produção. "Quando a mulher faz queijo, por exemplo, pode fazê-lo para comer ou vender" (Paulilo, 2004, p. 243).

Diante do que se apresenta, é central também considerar o fato de que atividades desenvolvidas por mulheres em contextos rurais começaram a ser reconhecidas como trabalho passível de direitos trabalhistas e previdenciários (salário-maternidade, auxíliodoença, aposentadoria por idade, entre outros), apenas na década de 1990, como resultado da intensa mobilização nacional de movimentos sociais rurais de mulheres (Salvaro, 2010). O que se evidencia é que a posição das mulheres como trabalhadoras rurais precisou ser produzida para que pudessem ser reconhecidas pelo Estado como sujeitos de direitos. E, especificamente, no âmbito de questões de gênero, na direção do que aponta Butler (2003), considerase a intensificação de ações coletivas na construção de determinada inteligibilidade cultural e reconhecimento do trabalho feminino.

Os processos de produção/reconhecimento de sujeitos e subjetividades podem ser lidos a partir de reflexões produzidas por Foucault (1995, p. 231), autor que teve como objetivo "criar uma história crítica dos diferentes modos pelos quais, em nossa cultura, os seres humanos tornam-se sujeitos". No que 
se refere à palavra sujeito, Foucault (1995, p. 235) se reporta a dois significados: "sujeito a alguém pelo controle e dependência, e preso à sua própria identidade por uma consciência ou autoconhecimento (...) ambos sugerem uma forma de poder $^{2}$ que subjuga e torna sujeito a". Sendo assim, a produção de uma subjetividade requer resistência às duas formas de sujeição apontadas.

No caso das lutas das mulheres pela produção/ reconhecimento como trabalhadoras rurais, verifica-se que precisaram entrar em determinado jogo político, nomear e provar a existência de um corpo que trabalha e, sobre tal aspecto, pode-se dizer da configuração de uma "biopolítica da população", conforme ressalta Foucault (2006, pp. 151-152): tratase de um poder sobre a vida, que, "por volta da metade do século XVIII, centrou-se no corpo-espécie, no corpo transpassado pela mecânica de um ser vivo e como suporte dos processos biológicos".

Explicitadas algumas das condições de possibilidade do trabalho feminino, principalmente em aspectos históricos que dizem da invisibilidade, necessidade de produção e reconhecimento da posição trabalhadora rural, parece importante indagar modos de participação de mulheres em cooperativas rurais virtuais, na medida em que, pela proposta de gestão democrática do trabalho, podem contribuir para a produção de relações mais igualitárias entre homens e mulheres.

No que diz respeito ao conceito de rural, a partir do que define Carneiro (2008, p. 35), considera-se o termo "ruralidade

2 A partir do que propõe Foucault (1995), o exercício do poder requer liberdade e uma relação de poder pode ser definida como uma ação sobre sua própria ação. sedes fixas, reúnem um grupo pequeno de agricultores (20 a 30) e movimentam uma quantidade pequena de produtos. Diferentemente de cooperativas tradicionais, que investem em uma pesada infraestrutura produtiva, com altos custos de gestão, em cooperativas virtuais, a especificidade de ativos "é oriunda de ativos humanos e localizados (...) assim, a relação contratual estabelecida acaba por basear-se em uma relação ética e pouco assimétrica, com presença do mercado nas relações terceirizadas de gestão ou no aluguel de infraestrutura" (Bialoskorski Neto, 2002, p. 16).

Tal perspectiva de cooperação busca assegurar autonomia de cada cooperado(a) no processo de produção como um todo, possibilitar a comercialização, padronização do uso da marca, aquisição de insumos, fornecimento de documentos, entre outras funções. Pesquisas realizadas em cooperativas de agricultores familiares da Região Sul de Santa Catarina evidenciam a crescente participação de mulheres como cooperadas (Estevam, Lazarini \& Kulkamp, 2011).

De acordo com Singer (2002, p. 89), "as cooperativas de produção são associações de trabalhadores, inclusive administradores, planejadores, técnicos etc., que visam produzir bens ou serviços a serem vendidos em mercados". Esse modelo de cooperativa, segundo Singer, é o "protótipo de empresa solidária", em que se pratica a autogestão, centralmente, voltada ao desenvolvimento humano de seus praticantes. Assim sendo, "participar das discussões e decisões do coletivo, ao qual se está associado, educa e conscientiza, tornando a pessoa mais realizada, autoconfiante e segura" (Singer, 2002, p. 21).

Sobre possibilidades de autonomia e igualdade social, Bialoskorski Neto (2012, p. 213) ressalta que "as cooperativas poderão oferecer à sociedade a oportunidade 
de incentivo a um sistema econômico diferente, mais igualitário e justo e, portanto, alternativo a uma economia competitiva, que marginaliza classes sociais e se apresenta como concentradora de renda".

Com base no exposto a respeito do tema e da perspectiva teórica que fundamenta o estudo, em consonância com o objetivo que orientou a elaboração do artigo, os tópicos seguintes tratam do método, dos resultados e discussão, considerações finais.

\section{Método}

A pesquisa foi de natureza qualitativa e os dados obtidos por meio da entrevista individual, com roteiro semiestruturado, com questões envolvendo o processo de criação e organização da cooperativa, assim como o cotidiano de trabalho nas Unidades de Produção Familiar (UPFs). No processo de localização e seleção dos sujeitos de pesquisa, optou-se pela amostragem por acessibilidade (Gil, 2010). Foram entrevistadas dez mulheres cooperadas, participantes de três cooperativas de agricultores familiares da Região Sul de Santa Catarina, no primeiro semestre de 2012. A localização dos sujeitos de pesquisa foi mediada pelas cooperativas. Em um primeiro momento, foram realizados contatos com os(as) presidentes(as) das cooperativas, explicitados os objetivos da pesquisa, com o intuito de identificar as associadas e convidá-las a participar. As entrevistas foram agendadas de acordo com a disponibilidade de tempo das entrevistadas e realizadas nas UPFs.

A pesquisa seguiu todos os procedimentos éticos exigidos pelo Comitê de Ética em Pesquisa com Seres Humanos (Número do parecer: 10204 - CAAE 01179912.4.0000.0119). Com a finalidade de manter o sigilo quanto à identidade dos sujeitos da pesquisa, no processo de apresentação e discussão dos dados, as entrevistadas serão apresentadas conforme a ordem de realização das próprias entrevistas, a saber: entrevistada 1 (E1); entrevistada 2 (E2); entrevistada 3 (E3); entrevistada 4 (E4); entrevistada 5 (E5); entrevistada 6 (E6); entrevistada 7 (E7); entrevistada 8 (E8); entrevistada 9 (E9) e entrevistada 10 (E10).

Na ocasião da pesquisa, as mulheres entrevistadas tinham idades entre 36 e 54 anos. Quanto à escolaridade, seis das entrevistadas tinham o ensino fundamental incompleto, duas o ensino fundamental completo, uma o ensino médio completo e uma cursava o ensino superior. Oito mulheres eram casadas, uma viúva e uma solteira. O número de filhos(as) por mulheres variou entre 1 e 3 .

As entrevistas foram gravadas, transcritas na íntegra e as informações foram analisadas por meio da análise de conteúdo. Conforme Bardin (2009), o processo de análise de conteúdo envolve três fases distintas e articuladas: pré-análise; exploração do material; tratamento dos resultados, inferências e interpretação. Com base nos objetivos do estudo, as análises individuais de cada entrevista possibilitaram a organização integradora dos conteúdos mobilizados pelas entrevistadas. Foi possível a identificação de categorias temáticas pelo agrupamento de conteúdos, conforme descrição que segue: a participação das cooperadas no processo de formação e em atividades das cooperativas, produtos comercializados pelas cooperadas; benefícios financeiros, sociais e subjetivos da participação nas cooperativas, profissionalização das mulheres, jornada e divisão do trabalho na unidade de produção, trabalho rural, direitos trabalhistas e previdenciários, a divisão do trabalho doméstico.

Para análise e discussão, as categorias identificadas foram agrupadas em duas categorias gerais: o processo de formação das cooperativas, participação e produtos 
comercializados pelas cooperadas; a participação de mulheres em cooperativas rurais virtuais - visibilidade social e reconhecimento do trabalho feminino. As categorias evidenciam questões teóricas centrais acerca da interface trabalho, gênero e produção de subjetividades. No entanto, é fundamental observar limites metodológicos em decorrência dos referenciais teóricos escolhidos, os quais remetem à produção discursiva de sujeitos e subjetividades. Sendo assim, ao tratar do conteúdo das entrevistas, buscou-se problematizar o sujeito que fala, bem como atravessamentos socioculturais que possibilitam a constituição de normas de gênero, sujeitos e subjetividades. Tais procedimentos foram utilizados com o intuito de lidar com concepções teóricas acerca das relações de gênero, da produção de sujeitos e subjetividades que mobilizam o processo de análise.

\section{Resultados e discussão}

O processo de formação das cooperativas, participação e produtos comercializados pelas cooperadas

De acordo com o Censo de 2010 (Instituto Brasileiro de Geografia e Estatística (IBGE), 2010), os municípios de origem das cooperativas e cooperadas entrevistadas têm as seguintes populações residentes totais: 22.548 (11.307 homens e 11.241 mulheres), 13.309 (6.719 homens e 6.590 mulheres) e 16.126 (8.078 homens e 8.048 mulheres). Na área agrícola, destacam-se o cultivo e o beneficiamento do arroz, milho, feijão, entre outros.

Como já descrito, as mulheres cooperadas integram três cooperativas de agricultores familiares da Região Sul de Santa Catarina. O tempo de cooperada variou entre 10 anos e um ano. Uma das cooperativas foi criada no início de 2004 e duas entre 2009 e 2011. Quatro das mulheres entrevistadas não participaram do processo de criação das cooperativas e se associaram posteriormente após convites para tal. A partir desse fato, é coerente sugerir que a "presença" das cooperativas nos municípios é positivada, desperta o interesse de agricultores(as) e possibilita integração de novos(as) cooperados(as). A decisão de se tornar uma cooperada, de acordo com as entrevistadas, foi apoiada por maridos, filhos(as), entre outros membros da família.

As mulheres que participaram dos processos de criação das cooperativas ressaltaram a centralidade de subsídios técnicos, mediados por profissionais de diferentes áreas e organizações, bem como de outras parcerias locais e regionais. Observaram que os processos de criação envolveram inúmeras reuniões e o trabalho conjunto dos(as) associados(as) e de diferentes parceiros. Essa observação sugere aspectos da complexidade do processo.

A pesquisa realizada por Estevam, Lanzarini e Kulkamp (2011) traz informações acerca de processos de formação de cooperativas em municípios da Região Sul de Santa Catarina e enfatizam a necessidade de inúmeras reuniões entre agricultores familiares, técnicos da Empresa de Pesquisa Agropecuária e Extensão Rural de Santa Catarina (Epagri) e prefeituras. O principal problema em questão se referia à comercialização dos produtos e a melhor forma de resolvê-lo foi por meio do trabalho de cooperação.

As cooperativas elaboram estatutos próprios, mas, em linhas gerais, verifica-se uma organização a partir de um Conselho de Administração (presidente, vice-presidente, 1 o e $2^{\mathrm{o}}$ secretários, $1^{\mathrm{O}}$ e $2^{\mathrm{o}}$ tesoureiros), Conselho Fiscal (membros efetivos e suplentes), eleitos por um mandato de dois anos. Nas cooperativas estudadas, o número de cooperados(as) varia entre 20 e 32 por cooperativa. Da população total de cada cooperativa, tem-se um universo de cinco a 12 mulheres. Uma das mulheres entrevistadas 
já foi presidenta da cooperativa, outras ocupam/ocuparam cargos nos conselhos de administração e fiscal.

É interessante refletir sobre o fato de que essas formas de participação das mulheres produzem "fissuras" no instituído acerca de normas e hierarquias de gênero, as quais atribuem posições sociais diferenciadas para mulheres e homens a partir da naturalização de "características femininas e masculinas." Nesse sentido, pode-se sugerir que a participação das mulheres em cooperativas, em um mesmo gesto, expõe desigualdades de gênero e possibilidades de superálas, por meio da diluição de hierarquias historicamente construídas.

É importante considerar também que a relação do(a) cooperado(a) com a cooperativa não se limita ao processo de comercialização. De acordo com os pressupostos que orientam as cooperativas rurais virtuais, os(as) cooperados(as) participam de diferentes processos de produção, organização e comercialização de mercadorias. Foi possível verificar que as cooperativas utilizam espaços locais nos municípios de origem para organização dos(as) cooperados(as) e, em alguns casos, também, para entrega e divulgação de produtos.

Para as entrevistadas 2 e 9, ocupar a posição de cooperada significou a possibilidade de mudança de atividades que eram desenvolvidas a partir de sistemas de integração agropecuários, tais como o plantio de fumo e a criação de frangos. Estevam et al. (2011), ao tratarem da formação de cooperativas rurais virtuais, destacam que estas possibilitaram retomar atividades "desenvolvidas pelos agricultores, muitas das quais já haviam sido abandonadas por causa da monocultura do fumo e/ou do arroz, devido às exigências legais (sanitárias e fiscais) que dificultavam a comercialização de muitos produtos, principalmente de origem animal" (p. 34).
As mercadorias produzidas e comercializadas pelas cooperadas entrevistadas incluem verduras, produtos de origem animal (salame, torresmo, entre outros), geleias, licores, suco de uva, vinagre, farinha de milho, bolachas, trufas, doces, pastéis, salgadinhos assados, rosca de polvilho, cuca alemã, pães, bolo. Os produtos são comercializados em feiras populares, programas do governo, supermercados, unidades comerciais próprias das cooperativas, festas locais, entre outros. Uma das cooperadas observou que determinadas datas, como natal e páscoa, contribuem para aumentar a demanda de comercialização de alguns produtos de panificação.

De acordo com a entrevistada 6, no processo de criação da cooperativa da qual faz parte, os(as) cooperados(as) fizeram um acordo para que não fossem comercializados os mesmos produtos por dois ou mais produtores. A entrevistada 9 observou que compra matériaprima de outros agricultores (manteiga, ovos, por exemplo) para preparar bolachas. A entrevistada 7 relatou que cultiva algumas das matérias-primas (frutas, hortaliças, entre outras) que utiliza na elaboração de geléias e licores.

Em grande medida, os produtos comercializados pelas cooperadas resultam de atividades domésticas femininas, tais como produzir alimentos, cultivar hortas, cuidar de animais de pequeno porte, entre outras destinadas à subsistência da família. Como descrito na introdução, segundo Paulilo (1987) o trabalho é considerado leve porque é realizado por mulheres ou crianças e envolve, especialmente, atividades relacionadas à subsistência. Conforme Bruschini e Ricoldi (2012, p. 263), "de certa forma, portanto, trabalho doméstico é aquele conjunto de atividades realizadas para dar conta de parte das responsabilidades familiares que se circunscrevem ao domicílio e ao arranjo familiar nele contido". 
Por outro lado, a pesquisa mostra que, na e pela mediação das cooperativas, tais mercadorias são produzidas a partir de outras condições de possibilidade, o que permite sugerir a positivação de determinada posição social historicamente desvalorizada. Sobre o uso de saberes em esferas consideradas produtivas, em artigo intitulado Cooperativismo - uma experiência feminina na arte de produzir conquistas, Lima (2012, p. 221) ressalta que mulheres cooperadas as quais estudou "transferem saberes já consolidados na esfera de atuação privada para esfera pública e assim criam as condições subjetivas favoráveis e necessárias ao desenvolvimento do empreendimento coletivo". De forma mais detalhada, essa possibilidade de "outro lugar de produção", ou seja, os processos de produção e profissionalização das mulheres cooperadas serão apresentados e discutidos por meio da categoria de análise que se segue.

\section{A participação de mulheres em cooperativas rurais virtuais: visibilidade social e reconhecimento do trabalho feminino}

A visibilidade social e o reconhecimento do trabalho feminino demonstram formas de organização coletiva, investimentos na profissionalização das mulheres, (re) significação de saberes e afazeres, a organização de novas jornadas e divisão do trabalho na unidade de produção. Como descrito na introdução, em contextos de trabalho rural, a condição de certa visibilidade social e reconhecimento do trabalho feminino remete a uma trajetória de lutas.

A visibilidade e o reconhecimento da participação feminina na esfera produtiva dão a ver lutas por reconhecimento e redistribuição. Na perspectiva teórica apontada por Fraser (2007), lutas por reconhecimento (sociocultural) e por redistribuição (econômica) apresentam um dilema, pois significam reivindicar e negar especificidades. A autora se refere ao fato de que desigualdades sociais são produzidas nas e pelas relações de classe, raça, gênero, geração, entre outros atravessamentos. No caso do trabalho feminino rural, a luta pelo reconhecimento social da profissão e a redistribuição econômica advinda daí, condição de possibilidade da igualdade social, fez-se em nome de determinada identidade social.

Tendo em vista a importância histórica do tema trabalho rural feminino, direitos trabalhistas e previdenciários, foram feitos alguns questionamentos ao longo da pesquisa e, em grande medida, as entrevistadas relatam conhecimentos parciais ou desconhecimento. Uma das entrevistadas tem um conhecimento mais amplo, pois atuou em um Sindicato de Trabalhadores Rurais. Sobre o assunto, por exemplo, a entrevistada 9 observa que "tinha que ter alguém que esclarece bem, isso aí. Como tu vai... Tu trabalha numa pequena agricultura familiar, numa cooperativa, como funciona teus direitos? Não está bem esclarecido pra mim".

As entrevistadas ressaltam os benefícios financeiros, sociais e subjetivos advindos da participação nas cooperativas. A legalização dos produtos, condição fundamental para a comercialização em feiras populares, supermercados, unidades comerciais próprias das cooperativas, festas locais, entre outros espaços, possibilitou benefícios financeiros mensais para as mulheres e suas famílias. A cooperativa se apresenta como uma possibilidade de organização e divisão coletiva das diferentes demandas legais (sanitárias e fiscais) implicadas no processo de produção e comercialização de determinadas mercadorias. De acordo com a entrevistada 4, a atividade de panificação, quando comparada a outras atividades agrícolas sazonais, é considerada economicamente positiva, pois possibilita uma 
É importante considerar que a atividade (profissional ou não) como prática social, na intersecção com gênero, produz subjetividades.

De forma recorrente, foi possível ler em relatos das mulheres entrevistadas ganhos

profissionais em termos de autonomia e liberdade, os quais refletiram em outras esferas da vida. garantia mensal de renda. A garantia de comercialização e o rendimento financeiro mensal promovem segurança para investir na unidade de produção, assim como na própria atividade.

É importante considerar que a atividade (profissional ou não) como prática social, na intersecção com gênero, produz subjetividades. De forma recorrente, foi possível ler em relatos das mulheres entrevistadas ganhos profissionais em termos de autonomia e liberdade, os quais refletiram em outras esferas da vida. A entrevistada 3 relatou que precisou "vencer" a insegurança e o medo para aprender a dirigir, exigência advinda de suas atividades laborais. Nesse caso, aprender a dirigir possibilitou também visitar com mais frequência a filha que reside em outro município. A entrevistada 1 relatou que a cooperativa se diferencia de uma fábrica, pois possibilita a interação com outras pessoas e o investimento em uma atividade que lhe é prazerosa.

Na e pela mediação da cooperativa e pela identidade cooperada, o trabalho, como prática social, confere visibilidade social e produção de novas formas de subjetividade às mulheres. Na perspectiva teórica apresentada por Foucault, Deleuze (2007, p. 116) esclarece que não se "emprega a palavra sujeito como pessoa ou forma de identidade, mas os termos 'subjetivação', no sentido de processo, e 'si', no sentido de relação (relação a si)". Processos de subjetivação indicam a constituição de modos de existência que não cessam de se recriar.

A partir do que discute Butler (2003), sobre a teoria feminista, a construção de uma identidade definida, compreendida pela categoria de mulheres - como sujeito do feminismo - objetiva representar e conferir visibilidade às mulheres, considerando que suas vidas eram mal representadas ou não representadas. Sem desconsiderar a importância do uso de tal identidade, Butler observa o fato de que o sujeito das mulheres não pode ser compreendido como permanente. Nas direções teóricas apontadas por Foucault (1995) e Butler, pode-se sugerir que o uso da identidade "cooperada" confere visibilidade social às mulheres na esfera produtiva e a possibilidade de outras formas de existência.

A visibilidade e o reconhecimento do trabalho feminino (e das mercadorias derivadas daí) são produzidos a partir de regras advindas do processo de legalização/ comercialização dos produtos, as quais exigiram a profissionalização das mulheres no sentido da realização de cursos específicos, entre outras demandas. Nesse caso, os regimes discursivos que produzem tais "sujeitos e mercadorias" dão a ver a determinada produção em esfera produtiva e não a esfera doméstica.

Algumas das entrevistadas relataram que o aprendizado da atividade foi anterior à participação na cooperativa, pela mediação de mães, avós, outros parentes e/ou mulheres com quem trabalharam. Mas foi possível verificar, também, investimentos na profissionalização em termos técnicos de produção e comercialização. Segundo alguns relatos, a realização de cursos de formação e/ ou qualificação profissional, muitos mediados pela cooperativa, contribuíram para a profissionalização dos(as) cooperados(as). Por exemplo, a entrevistada 1 se referiu ao curso de atendimento ao público e vendas. As entrevistadas 3 e 8 fizeram menção ao fato de que gostariam de fazer um curso de informática para auxiliar na atividade e consideram um desafio aprender novas tecnologias.

A participação nas cooperativas e a profissionalização das atividades desenvolvidas pelas mulheres remetem 
também à necessidade de organização de novas jornadas e divisão do trabalho na unidade de produção. Para algumas entrevistadas, as jornadas de trabalho podem ser longas e cansativas. Dependendo do tipo de produção, como no caso da panificação e do cultivo de verduras, são atividades que podem também ser minuciosas e exigirem cuidados específicos.

Em muitas situações, as atividades exigem muita responsabilidade, organização e ocupam grande parte do dia das cooperadas. Entretanto, quase que de forma unânime, as entrevistadas enfatizam que a realização das atividades é motivo de prazer e orgulho. Verifica-se que a jornada de trabalho se estende a partir das demandas do próprio trabalho e necessidades de produção. Em média, as mulheres relatam uma jornada diária de 8 horas. Porém, em situações específicas, como a exemplo da entrevistada 5, dois dias da semana exigem uma jornada ampliada e superior a oito horas diárias: “(...) são dois dias mais puxados, na segunda e na quarta (...) na segunda, é das duas da tarde e vai até dez horas da noite e na quarta-feira é das sete da manhã até as sete da noite".

As jornadas de trabalho são flexíveis e podem ser ampliadas ou não a partir da produção/ entrega de produtos. É interessante refletir sobre a lógica da organização do trabalho e as regras de produção de mercadoria na produção de subjetividades. Em artigo intitulado O tempo de trabalho em sua dimensão subjetiva, Lourenço (2010) destaca que "quando se busca entender os aspectos subjetivos na relação de homens e mulheres com o trabalho, a subjetividade ligada ao tempo de trabalho emerge como uma questão importante" (p. 199). Em sua análise, Lourenço (2010) faz menção ao tempo objetivo (mensurado pelo relógio) e "o tempo subjetivo, qualitativo, ou seja, o tempo vivido, ligado a dimensões afetivas e ao cotidiano em sua totalidade" (p. 207).
Na cooperativa estudada por Lourenço, tais "tempos" evidenciam contradições vivenciadas pelos trabalhadores, que prezam o tempo subjetivo, mas devem atender a determinadas exigências da lógica mercantil.

Outra questão que possibilita compreender a organização do trabalho nas unidades de produção envolve as exigências do mercado. A entrevistada 2 relata que o mercado exige um aumento na produção, o que implica levantamento de recursos financeiros, os quais nem sempre estão disponíveis aos agricultores(as). Além disso, as demandas de comercialização envolvem a necessidade constante de investimento técnico e financeiro. Em pesquisa sobre política de crédito rural em uma perspectiva de gênero, Hernández (2009) ressalta que o acesso ao Programa Nacional de Fortalecimento da Agricultura Familiar (Pronaf-Mulher) apresenta diferentes significados para as mulheres, especialmente no que se refere ao reconhecimento pelo Estado dos direitos como mulheres agricultoras. Cabe esclarecer que o Pronaf-Mulher é uma "linha específica de investimento disponível exclusivamente para as mulheres que se enquadravam em alguns grupos do Pronaf na safra 2004/2005 (...) a partir da safra 2005/2006, todas as mulheres, enquadradas em todos os grupos, têm direito a esse crédito especial" (Brasil, 2006, p. 28).

O acesso de agricultoras familiares a programas de financiamento, especificamente, ao Pronaf-Mulher, foi também objeto da pesquisa realizada por Zorzi (2008, p. 38), que se ateve ao processo de empoderamento relacionado "à possibilidade de inserção das agricultoras e uma política de crédito e à construção de um empreendimento econômico capaz de estabelecer uma nova posição para elas no espaço da família, do trabalho e da comunidade". Entre outras possibilidades e limites no processo de empoderamento, o estudo conclui que o fato de as mulheres 
Gesser (2004, pp.

164-165) realizou

um estudo

especificamente

sobre o êxodo

rural de mulheres

jovens em um

município de

Santa Catarina

e, entre outras

questões,

relaciona

êxodo rural e

desigualdades de gênero,

ressaltando que,

de modo geral, as mulheres

ainda ocupam

"uma posição

subordinada

dentro da família,

pois seu trabalho

é apenas

simples ajuda ao

coletivo, apesar

de apresentarem

uma jornada extenuante

de trabalho,

envolvendo as

lides agrícolas,

as atividades

domésticas e o

cuidado com os animais". iniciarem um empreendimento próprio não altera a posição do marido na família e propriedade.

Em perspectiva semelhante, nas unidades de produção, as cooperadas entrevistadas esclarecem como ocorre a divisão do trabalho. Em uma perspectiva mais geral, tal divisão envolve outras mulheres da família ou não, filhos e maridos. Uma das entrevistadas trabalha sozinha; outra relata que conta com a contribuição da irmã e da filha; outra com a ajuda esporádica da filha, outra, ainda, as filhas participam da atividade por meio da sugestão de novos produtos e no auxílio com a internet.

Para três cooperadas, as atividades de panificação desenvolvidas integram todos os membros da família e se transformaram na principal fonte de renda familiar. Cada membro da família, por exemplo, filho(a), marido, mãe da cooperada, é responsável por tarefas nas áreas da produção e comercialização dos produtos. Uma das cooperadas trabalha com o filho diariamente na produção e entrega de verduras. Duas cooperadas dividem com os maridos as atividades nas unidades de produção.

Alguns dos(as) filhos(as) das entrevistadas trabalham fora da propriedade e não têm interesse em prosseguir com as atividades desenvolvidas pelas mães e/ou famílias nas propriedades rurais. $\mathrm{O}$ (des)interesse de filhos(as) por atividades nas unidades de produção familiar rural sugere uma discussão a partir da problemática do êxodo rural juvenil.

O estudo de Stropasolas (2006), realizado no oeste do estado de Santa Catarina, evidencia um crescente êxodo rural juvenil. Entre os motivos observados pelos autores para o êxodo rural juvenil, destacam-se o tamanho reduzido da propriedade, as dificuldades de produção e comercialização, entre outros.
Gesser (2004, pp. 164-165) realizou um estudo especificamente sobre o êxodo rural de mulheres jovens em um município de Santa Catarina e, entre outras questões, relaciona êxodo rural e desigualdades de gênero, ressaltando que, de modo geral, as mulheres ainda ocupam "uma posição subordinada dentro da família, pois seu trabalho é apenas simples ajuda ao coletivo, apesar de apresentarem uma jornada extenuante de trabalho, envolvendo as lides agrícolas, as atividades domésticas e o cuidado com os animais". O estudo de Coradini (2008, p.186), realizado no Rio Grande do Sul, evidencia que "os homens formulam projetos de permanência na atividade agrícola mais do que as mulheres". O estudo de Froehlich et al. (2011), também Rio Grande do Sul, identifica processos de masculinização e envelhecimento da população rural.

Com base nos estudos apresentados, podese observar que determinado modelo de agricultura familiar contribui para o êxodo rural de jovens. No entanto, conforme dados da pesquisa que baseiam este artigo, em uma perspectiva de cooperação, a propriedade rural e a unidade familiar de produção são positivadas, como observa, por exemplo, a entrevistada 10, que compara o trabalho na unidade de produção familiar com o trabalho fora de casa e considera benefícios envolvendo a organização de tarefas da casa: "A vantagem é que não precisa pegar ônibus, está dentro de casa. Então, é fácil pra fazer o serviço porque tu estás dentro de casa".

De acordo com essa entrevistada, a atividade de produção para a cooperativa é intercalada com outras atividades da propriedade. Para a entrevistada 6, entretanto, o fato de a unidade de produção estar localizada ao lado da casa da família implicou o estabelecimento de jornadas e horários fixos: "Trabalhar perto de casa, não tinha horário. Acabava trabalhando assim, mas eu vi que não ia funcionar, que eu tinha que ter o meu trabalho num horário". 
As considerações apresentadas evidenciam a necessidade de problematizar constantemente a articulação entre atividade produtiva feminina e atividade doméstica. Como observado por Bruschini (2007), em primeiro momento, no Brasil os primeiros estudos sobre o trabalho feminino enfatizavam o trabalho produtivo sem articulá-lo com o trabalho doméstico; em um segundo momento, os estudos passaram a considerar que o trabalho produtivo e o lugar que as mulheres ocupam na sociedade também são determinados pelo papel que ocupam na família. Um salto qualitativo nos estudos pode ser evidenciado quando a esfera produtiva e esfera doméstica (ou reprodutiva) começam a ser articuladas. "Pois, para as mulheres, a vivência do trabalho implica sempre a combinação dessas duas esferas, seja pela articulação, seja pela superposição, tanto no meio urbano quanto no rural" (Bruschini, 2007, p. 542).

Em consonância com a literatura sobre o tema, os dados da pesquisa demonstram a relação intrínseca entre o trabalho doméstico e trabalho produtivo. De certo modo, a realização do trabalho produtivo é condição de possibilidade do trabalho doméstico e as mulheres, ainda, são as principais responsáveis pelo segundo.

Estudos como o de Hirata (2003) evidenciam que o trabalho formal da mulher no mercado de trabalho, não excluiu de forma alguma as tarefas realizadas antes no lar, pelo contrário, o que houve foi uma duplicação nas suas atividades, caracterizando-se assim uma dupla jornada de trabalho, principalmente, por ser destinado a ela o trabalho de menos qualificação, de repetição, monótono menos remunerado, com o mesmo nível de exigência do trabalho masculino e, muitas vezes, até mais insalubre.

Na situação em análise, em grande medida, a divisão do trabalho doméstico ainda ocorre "entre mulheres". O trabalho da casa e os cuidados com filhos(as) podem ser divididos com a sogra, mãe e/ou outras mulheres contratadas para tal fim. As atividades domésticas fazem parte de um conjunto de regras preestabelecidas e apreendidas no processo de constituição de mulheres.

Bruschini e Rocoldi (2012, p. 268) evidenciam que a reprodução da divisão sexual do trabalho doméstico entre filhos de ambos os sexos ocorre com diferenças: "a análise quantitativa revela que na faixa etária de 10 a 14 anos, 46\% dos meninos declararam cuidar de afazeres domésticos, mas a participação das meninas é muito superior - 78\% - em 2006".

De acordo com a definição de gênero apresentada por Butler (2003), podese considerar que, ao desempenharem atividades domésticas em uma perspectiva "naturalizada", as mulheres reiteram uma norma ou um conjunto de normas historicamente construídas. "O gênero é a estilização repetida do corpo, um conjunto de atos repetidos no interior de uma estrutura reguladora altamente rígida, a qual se cristaliza no tempo para produzir a aparência de uma substância, de uma classe natural de ser" (Butler, 2003, p. 59).

Em tal direção, na realização do trabalho doméstico, a contribuição do marido é considerada "ajuda", pois não se trata de uma atividade atribuída historicamente aos homens. O inverso ocorre, no meio rural, quando, por exemplo, as mulheres contribuem em atividades produtivas realizadas por homens. No que diz respeito à divisão do trabalho doméstico, uma das entrevistadas relata que conta com a ajuda da filha e realiza a maior parte das tarefas à noite, que é quando tem tempo livre. Em outra situação, mãe e filha são responsáveis pelas tarefas da casa, os filhos tomam conta de outras atividades, como a venda e a entrega de produtos nos locais de comercialização. 
Às vezes, por conta do volume de produção, a divisão do trabalho doméstico precisa ser reorganizada e requer o auxílio de maridos e filhos e, nesse caso, são consideradas como "ajuda", que podem ser consideradas como "força de trabalho de reserva". Sobre a divisão sexual do trabalho doméstico, Bruschini (2007) ressalta que pesquisas evidenciam o envolvimento dos homens em tarefas domésticas de forma seletiva, como ajuda ou cooperação.

De acordo com as mulheres entrevistadas, observa-se ainda que o trabalho é dividido a partir das necessidades e disponibilidade de tempo da família e, em alguns casos, contam com a contribuição semanal de uma diarista para a limpeza da casa. No caso específico de uma cooperada, a família toda contribui na divisão do trabalho doméstico, o que pode sugerir que a constituição da família (três homens e uma mulher) possibilita uma divisão sexual mais igualitária do trabalho doméstico.

Cabe ressaltar que o trabalho doméstico é realizado em períodos alternativos aos das atividades que envolvem a produção. No que diz respeito à articulação entre as atividades de produção e doméstica, de diferentes modos, as mulheres entrevistadas relatam que a unidade de produção é a prioridade, na medida em que, entre outras questões, possibilita o sustento da família.

\section{Considerações finais}

Diante de condições históricas de desvalorização social do trabalho feminino, a pesquisa sobre a participação de mulheres em cooperativas rurais se justificou na medida em que possibilitou analisar formas e relações de trabalho mais igualitárias em termos de gênero, classe, entre outros marcadores sociais. Entre outras questões, trouxe-se para o foco de análise o reconhecimento e a visibilidade do trabalho feminino.
A participação das mulheres entrevistadas em cooperativas rurais virtuais possibilitou a legalização da produção, condição fundamental para a comercialização. As mercadorias produzidas e comercializadas pelas cooperadas, entre outras, incluem verduras, frutas, produtos de origem animal, geléias, licores, suco de uva, vinagre, farinha de milho, bolachas, trufas, doces, pastéis, salgadinhos assados, rosca de polvilho, cuca alemã, pães, bolos. Os produtos são comercializados em feiras populares, programas do governo, supermercados, unidades comerciais próprias das cooperativas, festas locais, entre outros.

É possível considerar que as mercadorias produzidas e comercializadas são resultantes de determinadas atividades domésticas femininas. No entanto, na e pela mediação das cooperativas, tais mercadorias são produzidas a partir de outras condições de possibilidade, o que permite sugerir a positivação de determinada posição social historicamente desvalorizada. Em grande medida, os benefícios profissionais relatados pelas entrevistadas não podem ser lidos apenas pelo viés do rendimento financeiro. A participação em cooperativas, a possibilidade de exposição e comercialização dos produtos permitiram investimentos nas unidades familiares de produção, bem como na profissionalização das mulheres.

Apesar da manutenção da tradicional divisão do trabalho doméstico entre mulheres, a participação como cooperada contribui para a desconstrução de normas, hierarquias e desigualdades de gênero, produzidas a partir da naturalização de características femininas e masculinas (Butler, 2003). No entanto, de forma recorrente, a trajetória histórica de lutas mostra que oportunidades desiguais de trabalho e reconhecimento social encontram legitimidade em normas de gênero, as quais devem ser problematizadas e desconstruídas. Considerando que práticas sociais produzem 
modos de vida, sujeitos e subjetividades, espera-se com este artigo contribuir para o campo de estudos acerca da constituição de subjetividades nas intersecções com gênero e trabalho. Além disso, contribuir para o debate sobre o reconhecimento do trabalho feminino em contextos de cooperativismo rural, de modo a problematizar relações de trabalho (num contexto como o rural) que reforçam normas de gênero, naturalizam hierarquias e promovem desigualdades entre mulheres e homens. Como ressalta Foucault (1995, p. 239), "temos que promover novas formas de subjetividade através da recusa deste tipo de individualidade que nos foi imposto há vários séculos". Nesse sentido, o artigo trouxe para o foco de análise práticas sociais que se apresentam como condição de possibilidade para a igualdade de gênero e produção de outras formas de existência.

Giovana Ilka Jacinto Salvaro

Doutora em Ciências Humanas pela Universidade Federal de Santa Catarina. Docente pesquisadora da Universidade do Extremo Sul Catarinense, Criciúma - SC - Brasil.

E-mail: giovanailka@gmail.com

Dimas de Oliveira Estevam

Doutor em Sociologia Política pela Universidade Federal de Santa Catarina. Docente do Programa de Pós-Graduação em Desenvolvimento Socioeconômico (PPGDS) da Universidade do Extremo Sul Catarinense, Criciúma - SC - Brasil. E-mail: doe@unesc.net

\section{Daiane Fernandes Felipe}

Graduada em Psicologia pela Universidade do Extremo Sul Catarinense, Criciúma - SC - SP.

E-mail: daiane.fernandesfelipe@yahoo

Endereço para envio de correspondência:

Rua Celestina Zilli Rovaris, 185, Apt. 402, Centro. CEP: 88802-210. Criciúma, SC.

Recebido 03/12/2012, 1a Reformulação 06/05/2013, Aprovado 29/08/2013. 


\section{Referências}

Bardin, L. (2009). Análise de conteúdo. Lisboa/Portugal: Edições 70.

Bialoskorski Neto, S. (2002). Estratégias e cooperativas agropecuárias: um estudo analítico. In Seminário de Política Econômica e Agronegócios da UFV. Recuperado de http:// www.fearp.usp.br/ sigbial/inserir_out2002/Estrategias_e_ Cooperativas_Sig2.pdf

Bialoskorski Neto, S. (2012). Economia e gestão de organizações cooperativas. 2a. ed. São Paulo: Atlas.

Brasil. (2006) Plano Nacional de Políticas para as Mulheres Relatório de Implementação - 2005. Brasília, DF: Presidência da República. Secretaria Especial de Políticas para as Mulheres. Recuperado de http://www.sepm.gov.br/publicacoes teste/ publicacoes/2006/pnpm-relatorio.pdf.

Bruschini, M. C. A. (1993). Trabalho feminino: trajetória de um tema, perspectivas para o futuro. Trabalho apresentado no XVII Encontro Anual da ANPOCS, Caxambu, MG.

Bruschini, M. C. A. (2007). Trabalho e gênero no Brasil nos últimos dez anos. Cadernos de Pesquisa, 37(132), 537-572, doi: http:// dx.doi.org/10.1590/S0100-15742007000300003.

Bruschini, M. C. A. \& Ricoldi, A. M. (2012). Revendo estereótipos: o papel dos homens no trabalho doméstico. Revista Estudos Feministas, 20(1), 259-287. doi: http://dx.doi.org/10.1590/ S0104-026X2012000100014

Butler, J. (2003). Problemas de gênero: feminismo e subversão da identidade. Rio de Janeiro: Civilização Brasileira.

Brumer, A. (2004). Gênero e agricultura: a situação da mulher na agricultura do Rio Grande do Sul. Revista Estudos Feministas, Florianópolis, 12(1), 205-227. doi: http://dx.doi.org/10.1590/ S0104-026X2004000100011

Brumer, A.; Paulilo, M. I. (2004). Dossiê As agriculturas do sul do Brasil. Revista Estudos Feministas, Florianópolis, 12(1), pp. 171-330. doi: http://dx.doi.org/10.1590/S0104026X2004000100009.

Carneiro, M. J. (2008). "Rural" como categoria de pensamento. Ruris, Campinas, 2(1), 9-38. Recuperado de http://www.ifch. unicamp.br/ceres/2008-maria_carneiro.pdf.

Coradini, L. (2008). Autonomia e Projetos Profissionais das Joven na Agricultura Familiar do Rio Grande do Sul. In Brasil Presidência da República. Secretaria Especial de Políticas para as Mulheres. $3^{\circ}$ Prêmio Construindo a Igualdade de Gênero - Redações e artigos científicos vencedores (pp. 176188). Brasília, DF.

Cordeiro, R. de L. M.; Scott, R. P. (2007). Dossiê Mulheres em áreas rurais nas regiões Norte e Nordeste do Brasil. Revista Estudos Feminista, Florianópolis, 15(2), 419-490. doi: http:// dx.doi.org/10.1590/S0104-026X2007000200008.

Deleuze, G. (2007). Conversações. (6a. reimp.) São Paulo: Ed. 34

Estevam, D. de O.; Lanzarini, J. J. S. \& Kulkamp, R. (2011). Estudo do caso da Cooperativa de produção agroindustrial dos agricultores familiares de Forquilhinha - SC (COONAFOR). Sociedade e Desenvolvimento Rural, 5(2). Recuperado de http://www.inagrodf.com.br/revista/index.php/SDR/article/ view/130/105

Froehlich, J. M. et al. (2011) Êxodo seletivo, masculinização e envelhecimento da população rural na região central do RS. Ciência Rural, 41(9), 1674-1680. doi: http://dx.doi. org/10.1590/S0103-84782011005000124.

Foucault, M. (1995). O sujeito e o poder. In H. Dreyfus \& P. Rabinow, Michel Foucault: uma trajetória filosófica (pp. 231250). Rio de Janeiro: Forense Universitária.

Foucault, M. (2006). História da Sexualidade 1. A vontade de saber.

(17a. ed.) Rio de Janeiro: Edições Graal.
Fraser, N. (2007). Mapeando a imaginação feminista: da redistribuição ao reconhecimento e à representação. Revista de Estudos Feministas, Florianópolis, 15(2), 291-308. doi: http:// dx.doi.org/10.1590/S0104-026X2007000200002

Gesser, M. (2004). O êxodo rural dos jovens na agricultura familiar do município de lontras: análise psicossocial. Dissertação de Mestrado. Programa de Pós Graduação em Psicologia Social, Pontifícia Universidade Católica de São Paulo, São Paulo.

Gil, A. C. (2010). Métodos e técnicas de pesquisa social.(6a. ed.) São Paulo: Atlas.

Hernández. C. O. (2009). Política de crédito rural com perspectiva de gênero: um meio de "empoderamento" para as mulheres rurais? Tese de Doutorado. Programa de Pós Graduação em Desenvolvimento Rural, Universidade Federal do Rio Grande do Sul, Porto Alegre - RS. Recuperado de http://www. lume.ufrgs.br/bitstream/handle/10183/16405/000696957. pdf? sequence $=1$.

Hirata, H. (2002). Nova divisão sexual do trabalho? Um olhar voltado para a empresa e a sociedade. São Paulo: Boitempo.

Instituto Brasileiro de Geografia e Estatística -IBGE. (2010). Censo Demográfico 2010. Recuperado de http://www.ibge.gov.br/ cidadesat/topwindow.htm?1.

Lima, M. da S. (2012). Cooperativismo: uma experiência feminina na arte de produzir conquistas. Revista Estudos Feministas, Florianópolis, 20(1), 209-232. doi: http://dx.doi.org/10.1590/ S0104-026X2012000100012

Lourenço, M. L. (2010). O tempo de trabalho em sua dimensão subjetiva. Psicologia USP, 21(1), 199-215. doi: http://dx.doi. org/10.1590/S0103-65642010000100011.

Melo, H. P. de. (2009) Invisibilidade do trabalho feminino: uma violência disfarçada - notas preliminares. In C. S. Tornquist et al (Orgs), Leituras de resistência: corpo, violência e poder (pp. 165-184). Florianópolis, SC: Ed. Mulheres.

Paulilo, M. I. S. (1987). O peso do trabalho leve. Revista Ciência Hoje, Rio de Janeiro, SBPC, 5(28), 64-70.

Paulilo, M. I. S. (2003). Movimento de Mulheres Agricultoras: Terra e Matrimônio. In M. I. S. Paulilo, W. Schmidt (Orgs), Agricultura e espaço rural em Santa Catarina (pp. 15-38). Florianópolis, SC: Ed. da UFSC.

Paulilo, M. I. S. (2004). Trabalho familiar: uma categoria esquecida de análise. Revista Estudos Feministas, Florianópolis, 12(1), 229-252. doi: http://dx.doi.org/10.1590/S0104026X2004000100012

Salvaro, G. I. J. (2010). Entre a igualdade e a diferença: mulheres camponesas em lutas de gênero. Tese de Doutorado. Programa de Pós-Graduação Interdisciplinar em Ciências Humanas, Universidade Federal de Santa Catarina. Florianópolis, SC.

Scott, J. W. (1995). Gênero: uma categoria útil de análise histórica. Revista Educação e Realidade, Porto Alegre, 20(2), 71-99.

Singer, P. (2002). Introdução à Economia Solidária. São Paulo: Editora Fundação Perseu Abramo.

Souza-Lobo, E. (2011) A classe operária tem dois sexos: trabalho, dominação e resistência.( 2a. ed.) São Paulo: Editora Fundação Perseu Abramo.

Stropasolas, V. L. (2006). O mundo rural no horizonte dos jovens. Florianópolis, SC: Ed. da UFSC.

Woortmann, E. F. (1995). Herdeiros, parentes e compadres. São Paulo: Hucitec; Brasília, DF: Edunb.

Zorzi, A. (2008). Uma análise crítica da noção de empoderamento com base no acesso das agricultoras ao PRONAF Mulher em ljuí/RS. Dissertação de Mestrado. Programa de Pós-Graduação em Sociologia, Universidade Federal do Rio Grande do Sul, Porto Alegre - RS. Recuperado de http://www.lume.ufrgs.br/ handle/10183/15005. 